\title{
Social media and social networking applications for teaching and learning
}

\author{
Michelle Mei Ling Yeo \\ Education Faculty, Monash University, Melbourne, Australia \\ For correspondence: yeomeiling1@gmail.com
}

\begin{abstract}
:
This paper aims to better understand the experiences of the youth and the educators with the tapping of social media like YouTube videos and the social networking application of Facebook for teaching and learning. This paper is interested in appropriating the benefits of leveraging of social media and networking applications like YouTube and Facebook for learning and pedagogical purposes. To find out the viability of the uses of YouTube videos and Facebook postings as informative and communicative tools, this paper employs a case study of a qualitative method of informal interviews with tertiary students who are studying Business Communication modules from two polytechnics and interviews with lecturers who are teaching Communication modules in two other polytechnics and a University, in Singapore. The results of the data indicated students' preference with using YouTube videos and Facebook to make friends, to network with friends and to be able to learn additional knowledge at their own time and at their preferred place. They like to learn informally via the YouTube videos and Facebook postings with the information and knowledge that extend beyond the boundaries of the textbook and the classroom. But, the problems with the leveraging of YouTube and Facebook for learning include the distractions that would "take away the learning time" from the myriad of games and the various social invitation available on YouTube videos and Facebook. The data also indicated that the youth; the students and the lecturers are positive about using Facebook as a "social" platform to build a good relationship with one another, outside of school. According to the data, the connectivity and the communication via Facebook allow for the students' and lecturer's ease of being friends with one another and with the ease of sharing information and knowledge beyond the boundaries of the classroom and the textbook. Hence, the Facebook connectivity and communication between the students and the lecturers enable a good relationship and in building better rapport between the students and lecturers. However, both the students and lecturers strongly indicated the necessity of face-to-face lessons for communication and for facilitation of academic and formal learning. In conclusion, the ability to read and write and classroom interactions, teaching and having face-to-face communication are in fact still very vital and important but it is no longer sufficient. Old literacy and old technologies are augmented but not totally replaced. There can be a mix of blending the old and new literacy with the social media and social networking applications in the $21^{\text {st }}$ century for teaching and learning.
\end{abstract}

Keywords: YouTube, Facebook, Youth Culture, Social-Media Networking and Communications, Informal learning and Learning Technologies.

\section{Introduction}

The aim of this paper is not just a discussion about the transition from the "traditional" learning of "chalk and talk" and "teacher-oriented pedagogy" to "electronically-mediated learning". But, this paper discussion is interested in appropriating the benefits of leveraging of social media and networking applications like YouTube and Facebook for learning and pedagogical in the $21^{\text {st }}$ century society. The change in the socio-economic and education environments necessitates a consistent and continual search for different and innovative teaching strategies to address the learning requirements of the future generations of students who are technically inclined and driven. Using a qualitative method of semi-structure interviews with keen participants of youth, whose age ranges from 18 to early 20s, from two polytechnics and four lecturersteaching in two other polytechnics and a University, in Singapore, who have the experiences with the use of YouTube videos and who have Facebook account and experiences. This papers seeks to explore and understand the learning experiences of the youth; the polytechnic studentsand the educators; the lecturers with the leveraging 
of media and social networking applications like YouTube and Facebook for teaching and learning through a qualitative method of informal and semi-structured interviews.

A qualitative research method, according to Merriam (1998), is exploratory, inductive with emphasis on processes instead of the end result, so that there will be no predetermined hypotheses, and "what one does is to observe, intuit, sense what is occurring in a natural setting" (Merriam, 1998, p65). To collect data, sampling of participants is an essential part of doing the research. For the purpose of this paper, a sample of five tertiary students studying the similar Business Communications from two different polytechnics and four lecturers teaching Communication Modules at different polytechnics and a particular University in Singapore, which is representative of a larger population of students and educators, were invited as participants for the informal and semi-structured interviews. The student participants were studying similar Business Communication modules and the lecturers were teaching Communication modules and have had experiences with the use of YouTube videos and with Facebook account and experiences in their daily lives. The choice of the participants with similar learning and teaching background and environment ensures validity of the sample participants for this paper. The conduct of the interviews was guided by the interview protocol, with key questions and topics to be covered in the interview and the interviews were recorded using a mobile phone voice-memo recorder. Thus, this paper is an exploratory study with a case study of students and lecturers' experiences, opinions and preferences with teaching and learning via the YouTube videos and the Facebook connectivity and wall-to-wall postings for teaching and learning. In the meanwhile, the paper also seeks to understand the possible problems and difficulties that the students and lecturers would have experienced with the leveraging of these social media and social networking applications for teaching and learning.

O'Hanlon (2007) suggests that the implementation of social media technologies, specifically social networking, is what students are using every day and it is this social setting that breeds the students' intrinsic and extrinsic motivation to use technologies for learning. Simonson et al. (2000) describe online learning and social networking tools as more convenient than the traditional classroom learning (the use of textbooks for learning) because of the availability of online materials and 24 hour access to learning.

Similarly, from the data the youth or the students indicated that they liked to use the YouTube videos for informal learning for information and knowledge that extends beyond the boundaries of the classroom and the textbook. The other reasons for students' preference to use the YouTube videos and Facebook postings are: the ease of accessing out of textbook information, the abundance of information available online, the ease of sharing information and the availability of online materials at one's own time and at their preferred place and in using YouTube videos for informal learning of information and knowledge.

The finding from the data also indicated that the students and the lecturers were positive about using Facebook as a "social" platform to build a good relationship outside of school with the Facebook connectivity and the postings. They felt that the connectivity and the communication via Facebook allow for students' and lecturer's ease of being friends with the ease of sharing information and knowledge with one another that extends beyond the boundaries of the classroom and the textbook. Hence, the Facebook connectivity and the Facebook communication between the students and the lecturers enable a better rapport between students and lecturers.

Oblinger (2006) points out that the characteristics of the $21^{\text {st }}$ century youth are technologically inclined and have a high preference for active and participatory experiences of both face-to-face as well as online learning. This high preference for a participatory experience via the Web does not mean that the youth need to be online synchronously or be together physically. Rather, the youth or the students can be discussing, communicating and sharing information and knowledge synchronously or asynchronously using the various social media and networking applications at any time and at any location. Similarly, from the data, the students indicated that they liked the active participatory experiences of using the social media and social networking applications at any time and at any place. They liked to use YouTube for additional informationand knowledge that can better prepare them for 
the real working world. They liked to use the social networking applications of Facebook to make friends and to network with friends and to have a good relationship and rapport with their lecturers, too. Through the connectivity, network and communication via Facebook, they can get to learn about information and knowledge informally at their own time and at their own preferred place beyond the boundaries of the textbook and the classroom.

\section{YouTube Videos and Facebook Connection}

\section{Video Sharing Sites - YouTube}

Today's youth have much experience with video and photo-sharing media such as YouTube (Mullen \& Wedwick, 2008). This video-sharing media can be incorporated into a constructivist classroom as learning tools as the youth; the students are actively creating their own learning experiences through viewing and creating videos and educators can use this as a tool for engaging the youth in meaningful learning experiences (Mullen \& Wedwick, 2008).

YouTube is increasingly being used by educators as a pedagogic resource for many interesting newsworthy events to teach students especially within an 'English as a Second Language' course, (Duffy, 2008). The students watched the videos as a resource towards learning the essentials of the English Language and the students get enjoyment from watching the videos. There was positive students' feedback about the learning of English as a Second language through the YouTube videos (Duffy, 2008). To Duffy (2008), videos can be a powerful educational and motivational tool but the effectiveness of You Tube is not in itself but in how it is used towards achieving learning goals and objectives before it can be seen as an effective learning tool. Effective instructional video is studentcentred and can be used for student pedagogy with the video as a vehicle for students' discovery of knowledge and for instructional videos on an online space to share student authored content (Duffy, 2008). With the discourse on the use of YouTube videos for learning now and in the future, educators may want to consider how to engage students with YouTube to teach students to think critically about their potential uses of YouTube videos for collaborative and meaningful social learning experiences with one another.

Social NetworkingApplication - Facebook

Besides the use of YouTube videos for collaborative students' learning experiences, Facebook also shares many of the qualities of a good education technology in its reflective element, allowing for peer feedback and a fit for the social context of learning. The conversational and collaborative characteristics of Face book are also "collaborative and encourage active participatory role for users" (Maloney 2007, p.26). According to Stutzman (2005), students use Facebook to 'hang out' with friends, learn about each other or simply as a directory to other websites and knowledge. Students often use Facebook for social purposes to develop social networking skills with their peers at school and from previous institutions they have attended. Students' use of Facebook is profoundly informal and often at a tangent with the official learning aims of educators (Stutzman, 2005).

It seems that the formal use of Facebook as a tool for rigorous academic study is fairly rare, but the use of Facebook as a tool for teaching and learning has been on the rise recently. According to Selwyn (2009), Facebook is very useful as a tool for negotiating a social and community identity, such as student identity as a university student. Selwyn (2009) conducted an extensive survey of the contents of Facebook postings by 909 undergraduate students in the U.K and found that the students would use Facebook particularly to negotiate their identity as a university student by sharing feelings and perceptions about the institution and teaching staff. Hence, the study has not been able to extensively show that Facebook is fully welcomed as a good teaching and learning pedagogy.

However, with the advent of social media and networking applications, the youth are actively using these applications and are connected with one another via these applications. A survey by Singapore Polytechnic's School of Communication, Arts and Social Sciences (2009) found that 71\% of 201 respondents between 15 and 19 years old and $74 \%$ of 175 respondents between 20 and 24 years old visited Facebook daily. The majority of the 800 respondents (15-34 years old) shared their personal information such as real name, age, gender and date of birth on their Facebook page (Singapore 
Polytechnic, 2009). But, are students able to learn from the sharing and discussion of information via Facebook with one another? What could possibly be the problems and difficulties with using of YouTube videos and Facebook application for learning purposes? There seems to be a gap in the literature about the use of YouTube and Facebook for learning among the youth (Singapore Polytechnic, 2009; Selwyn, 2009). Hence, this paper aims to seek an in-depth understanding, in exploration through a qualitative method of interviews, of the tertiary students' learning experiences and opinions with the social media of YouTube videos and the social networking applications of Facebook for learning. Secondly, the paper also aims to seek an in-depth understanding of lecturers' experiences and opinions of using YouTube videos and Facebook for teaching. Thus, the exploratory study and investigation of a case study of students and lecturers' experiences, opinions and preferences with teaching and learning via the YouTube videos and the connectivity and communication via Facebook for teaching and learning for this paper. In the meanwhile, the paper also seeks to find out the possible problems and difficulties that the students and lecturers would have experienced with the leveraging of these social media and social networking applications for teaching and learning.

\section{Theoretical Aspect - Social Learning with Social Media and Networking Applications}

From a theoretical aspect of discussion, leveraging on social media and innovative technologies for communication and for students' learning results in a strong application of many of the concepts found within social constructivism (Vygotsky, 1978). For social constructivists, knowledge is constructed within a social context and the knowledge construction is usually and always collaborative.According to Jonassen et al (1999), students learn with learning technologies when these can support knowledge construction (e.g. representing students' ideas, understanding and beliefs, and producing organized, multimedia knowledge bases being produced by students). Students learn by conversing using technologies (e.g. collaborating with others, and discussing, arguing and building consensus among members of a community, and supporting discourse among the knowledge-building communities); and they also learn by reflecting with learning technologies (e.g. helping students to articulate and represent what they know and supporting students' internal negotiations and meaning making) constructing personal representations of meaning, and supporting mindful thinking (Jonassen et al., 1999). The use of YouTube videos can be leveraged as an educational and motivational tool towards achieving learning goals and objectives that is studentcentred and can be used for student pedagogy with the video as a vehicle for students' discovery of knowledge and for instructional videos on an online space to share student authored content (Duffy, 2008; Mullen \& Wedwick, 2008).

According to Seitzinger (2006), the term 'constructivist learning tool' has also become associated with the communicative and collaborative tools of learning technologies, particularly social networking applications' chat walls, in that they have the key characteristic of allowing students to develop and maintain their own content online while discussing and communicating with one another for information and knowledge or for collaborative learning. With the exposure to a greater diversity in perspectives through participation in global discourse, the students' outlook will become less parochial and worldlier (Seitzinger, 2006). However, to maximize the benefits of these technologies and tools means that students should be encouraged to communicate and collaborate within the learning context.

This process of student learning in collaboration with another individual while reflecting on, communicating and articulating what they have learnt from the social media and networking applications is used as the context in this paper of finding out the tertiary students' experiences and opinions together with the lecturer's opinions with leveraging of the social media and social networking applications. Can YouTube videos and Facebook be used for teaching and learning effectively and meaningfully within a theoretical aspect of social constructivism of learning with one another? What could possibly be the problems associated with using the YouTube videos and Facebook for both teaching and learning? 


\section{Data and Discussions - Informal Learning and Social Connections with Friends and Lecturers}

Academic engagement through the Facebook postings proved not to be exclusively scholarly within the formal context of school assignment and school-related performance. The students would use the online space to socialise with peers and to inform one another in general and in authentic knowledge generation and information seeking context instead.

From the data, the youth, the students liked to be connected with one another using Facebook to make friends and to learn from one another. They also liked to use YouTube videos for informal learning, the learning of information and knowledge that extends beyond the knowledge learnt in school and from the textbook. But, the students did not think highly of using YouTube and Facebook for formal learning academically. However, there can be informal learning where there is learning about "knowledge of the world" and "life's lessons" from the YouTube videos. The students indicated that they liked to use the information and knowledge from YouTube videos and Facebook connections and postings as informal learning that would also better prepare them as the future workforce of the social context of the $21^{\text {st }}$ century. This is parallel to the literature that the YouTube videos can be powerful educational and motivational tool for the students to partake in the creation and sharing of videos for self-discovery and for knowledge through active participation of the social media (Duffy, 2008; Mullen \& Wedwick, 2008).

To the students, the Internet and the social media networking applications are not only just a haven from the outside world of education but are seen more as a network of informal connections that crossed the boundaries of learning, work and leisure. The students were tapping into the interactive media and the social networking tool for informal socialization with peers and the knowledge community, namely, their lecturers, especially with Facebook for communication, for general and informal information gathering and content sharing. This knowledge was identified by both the students and the lecturers as informal learning. This echoes some of the literature of the informal use of Facebook (Selwyn, 2009), whereby the students' main use of Facebook was to maintain relationships with existing known friends, and their reported use of Facebook for entertainment purposes, to vent their emotions and to 'hang out' with their friends and for social purposes (Stutzman, 2005).

Similarly, the data indicates that Facebook was one of the students' preferred social media networking applications as it enabled them to create a social identity online which enables socialization and interactive communication for learning about general information and in preparing them for the real world.

From the lecturers' interviews, the information sharing and provision is not necessarily the exclusive preserve of the lecturer (educator) now but the presence of the lecturer as a facilitator and as a friend in guiding the students towards knowledge and learning in general through the various YouTube videos and the communication platform of Facebook. However, both the use of YouTube videos and the Facebook wall-to wall postings online are not deemed as a suitable pedagogical tool for discussing formal school assignments and neither is it often used as a discussion platform about rigorous and formal assignment criteria online.

The following are some snippets of the interview transcripts that support the data of the students' and the lecturers' use of the social media and the social networking applications for social purposes of being friends, in networking and in enhancing a good rapport and relationship between the students and the lecturers as friends.

The online connectivity via the Facebook connections between the lecturers and the students to be "friends" help to build a better a good relationship and a good rapport between the students and the lecturers.

For my students, the transition from secondary level to polytechnic means that the way they view teachers/lecturers are also different. They may not treat us like teachers...

(Lt4.m5a09.01sec) 
The fact that we can know what is happening in their lives via Facebook, gets us one step closer to them so it helps in nurturing that relationship, which in turn, works better when we are in class, too.

(Lt4.m5a11.38sec)

The lecturers felt that with the online connectivity and sharing of the wall-to-wall wall postings, the Facebook connections with students and in communicating online via the wall-to-wall postings would allow them to know and understand the students better.

When I interact with them on Facebook, it allows me to gain insights into their personal life... allows more casual conversations when I next meet them in class. They feel a personal connection, especially those who are quieter in class, or those I don't usually interact with in class...

(Lt1.m5a, 10.04sec)

It serves a social function that allows us to know the students on a personal level and vice versa. Students come up to talk to me about certain topics.... Topics may not revolve around what I teach so it allows me to hear their views about topics outside of class....

(Lt1.m5a, 12.48sec)

Regardless of the use of the social media as tools for interaction and communication there is still the need for all educators to maintain the professionalism of an educator in inspiring, motivating and facilitating learning while remaining as "friends" via Facebook.

I keep my personal and work FB accounts separate so.... I can still keep a professional front....We can talk about K-Pop or music on FB but that does not mean I will give them additional marks or preferential treatment in class.

(Lt2.m5a.21.06sec)

Besides the use of Facebook as a social networking application for the closer rapport and good professional student and teacher relationship for understanding of the students, there is essentially a need for face-to face communication with the students for a more rigorous and formal learning context.

The students are easily distracted on Facebook. ..For face-to-face communications... in general, they can concentrate and focus more and they can also ask questions either during lesson or after class on a one-on-one session....

(Lt4.m5a14.22sec)

There are more eye contact and body language to signal to the teachers whether the students are with you on the topics and on lessons learnt in class... The classroom environment facilitates more learning meant for assessment and for requirements of the assignments. You can't discuss much formal criteria for assessment online via Facebook.

(Lt3.m5a21.07sec)

The use of wall-to-wall Facebook postings are more for social interaction with little or no formal learning related to the academic assessment, course of study.

But there is a wider scope and general learning about knowledge beyond the text with the autonomy of learning towards students' ownership of learning in a student-centred learning.

Links to videos or articles that are related to Marketing Communications, Advertising, Public Relations modules, etc or about the latest gadgets or social media news which are general knowledge and additional knowledge besides the text materials and classroom discussions...

(Lt2.m5a28.01sec)

One of the main benefits is that since many students know how to use it, the learning curve for using such a tool will not be steep. They are able to source for additional information via the sharing of posts and they are trying to learn more from one another.... They are also more willing to use it.

(Lt3.m5a.16.02sec) 
Similarly, the youth, the students liked to be connected with one another using Facebook to make friends and to learn from one another. They also liked to communicate with one another using the Facebook postings to learn about information and knowledge that extends beyond the knowledge learnt in school and from the textbook.

Like more sharing and communication between all for knowledge of the world than just information from the textbooks and curriculum....

(E3.m4a, 35:01sec)

I like the social interactive aspect of sharing and openly discussing interesting topics on Facebook and preparing myself for the real working world. Learning using Facebook postings would be an enriching experience that no textbooks could provide.

(J3.m4a, 16:21sec)

The students indicated that they liked to use the information and knowledge from the Facebook connections and postings as informal learning that would also better prepare them as the future workforce of the social context of the $21^{\text {st }}$ century.

The Internet and the social media networking applications were not only just a haven from the outside world of education but were seen more as a network of informal connections that crossed the boundaries of learning, work and leisure.

More and more institutions and schools should consider setting up Facebook accounts as a platform for more sharing, learning and communicating of knowledge with one another.

(E3.m4a, 35:09sec)

I learn much more from Facebook as more people are interlinked and connected.

(J3.m4a, 16:22sec)

I would sometimes learn life's lessons through watching the videos.

(D2.m4a, 17:29sec)

How to do certain things and on how to prepare the graduating students to prepare and how to behave professionally for a job interview through the YouTube videos... $\quad$ (J2.m4a, 15:31sec)

The students were tapping into the interactive media and the social networking tool for informal socialization with peers and the knowledge community, especially with the use of the YouTube videos and the Facebook connections for communication, information gathering and content sharing that are informal but knowledge that pertains to the real working world and in preparation of students' future after graduation.

\section{Discussions - Problems of Distractions and Unreliable information for Formal Learning}

The students were distracted with the myriad of online games while using the YouTube videos for learning. Distraction can also be in the form of social invitation which is a feature of the various social networking activities, like Facebook. The students thus identified that the problems of these distractions actually 'take away' their learning time when they were using the YouTube videos and the Facebook applications.

Distractions such as games and videos on both Facebook and YouTube would take away most of the time meant for doing research and for reading of information and knowledge.

(P2.m4a, 39:58sec)

But, learning or gathering of knowledge through Facebook is quite difficult and tough to concentrate because of the distractions of games.

(D3.m4a, 19:21sec)

Many of my friends will get invited to play the games on Facebook so, this distraction actually take away learning time.

(J4.m4a, 21:04sec) 
The students did not think positively of using the YouTube videos and Facebook applications for formal learning related to academic study due to the informal and social use of these applications with many different people and networks online. In fact, the students did not fully credit the postings and information as reliable and credible. They have voiced major concerns over the legitimacy of reliable information from the YouTube videos and the Facebook postings for schoolwork. The students would be very cautious before citing the information as academic formal reference and would refer to the information and knowledge as informal knowledge and mentioned that the Facebook postings to be taken with "a pinch of salt".

Facebook is not considered as a formal learning tool, as friends or classmates would not take the posts too seriously as information meant for learning.

(P2.m4a, 38:51sec)

Facebook is used more appropriately for social interaction and not for educational purposes of learning for students.

(D2.m4a, 19:07sec)

I will not use YouTube to help me prepare for my tests or examinations.

(J2.m4a, 15:33sec)

Take it with a pinch of salt; these fun comments... I feel that the YouTube videos are unpleasant at times and too uncouth for some young viewers and so there are not many educational videos worth watching.

(J.m4a, 17:33sec)

The lecturers have also identified the following problems of distractions and that the use of YouTube videos and Facebook as not compatible and suitable for formal learning of academic related matters. I think it is engaging in the social aspects but not so much for teaching... Students are having a good time away from school when they should be... When they are in class... but they are online on "Weibo"...better to use a different platform if the focus is for schoolwork.

(Lt3.m5a.15.03sec)

One of the main issues is that Facebook is primarily a social tool. I am not sure students would view and use it as a learning tool.

(Lt5.m5a.08.05sec)

YouTube videos and Facebook can be an engaging and interesting tool for teaching, but as a potential tool for learning, not so....

(Lt5.m5a.11.27sec)

The problems of distractions, the abundance of information, and the open nature of the collaborative social creation of knowledge with many users editing, changing and sharing information could have contributed to the unreliable and not credible knowledge meant for meeting the criteria of the formal assessment of school-related assignments and content, the use of YouTube videos and Facebook can be used more for learning beyond what is taught within the classroom and the textbook which is also identified as informal learning. The informal learning of information and knowledge via the various YouTube video and Facebook are deemed to better prepare the students as the future workforce, for authentic and real working world and for "life's lessons" and on "knowledge of the world".

Although there are problems and difficulties brought about by the abundance of distractions, the online social invitations and games, as well as the unreliable of information online sometimes due to the abundance of information and with the social collaborative nature of sharing and editing information and knowledge, the use of YouTube and Facebook are not entirely without its social, collaborative and educational uses at all, too.

The literature reviews of other researches have also suggested that students' use of Facebook is to build on their network with friends and to maintain existing relationships (Selwyn, 2009). Students reported using Facebook to keep in touch with people who they had already shared an offline connection with; with classmates and even with friends who they have known (Bosch, 2009; Pempek et al., 2009). Besides the social aspect of expanding and broadening the horizon of friends, technology 
can be used to present to an audience (using multimedia authoring tools) and, to enable for collaborative learning and working with others (such as the use of discussion forums and chats (Gee, 2004; Lankshear\&Knobel, 2004b) and with social networking applications like Facebook.

However, that is not to say that the concept of classroom face-to-face communication and teaching in the classroom setting is not important in the $21^{\text {st }}$ century or that the concept of communicating and teaching face to face is obsolete. But, the use of social media and social networking applications can be maximized with in class face to face learning and that there can be a blend of using both the social media and social application with learning in the classroom setting. From the data, besides the use of Facebook as a social networking application for the closer rapport and good professional student and teacher relationship for understanding of the students, there is essentially a need for face-to face communication with the students for a more rigorous and formal learning context.

In conclusion, the ability to read and write and classroom interactions, teaching and having face-toface communication are in fact still very vital and important but it is no longer sufficient, as discussed from the perspectives, opinions and experiences of the students and the lecturers. The concept of 'new literacy' is the ability to collaborate and interact with others, and to think critically about the world that we live in (Gee, 2004; Lankshear\&Knobel, 2004b). Since the students like learning socially together through the network of peers, friends and the knowledge community, like their lecturers, sharing and in learning from one another as espoused in the theoretical aspect of social constructivism (Vygotsky, 1978), the students are also exposed to a greater diversity in perspectives through participation in global discourse thus enabling the students' outlook to be more worldlier (Seitzinger, 2006). However, to maximize the benefits of these technologies and tools means that students should be encouraged to communicate and collaborate actively within the learning context of learning in collaboration with another individual while reflecting on, communicating and articulating what they have learnt from the social media and networking applications.

New technology enables shifts at the level of pedagogy delivery that old literacy and old technologies are augmented but not totally replaced. Hence, the following are some recommendations for the use of YouTube videos and Facebook for both learning and teaching pedagogies for a mix of blending the old and new literacy with the social media and social networking applications in the $21^{\text {st }}$ century.

\section{Recommendation}

From the discussion of the data and the literature of the use of social media (YouTube) and social networking application (Facebook), we can see the strengths of using the social media for communicating with one another to build better rapport and maintain friendly relationships between the students and their peers and with their lecturers. From here, there could be learning at any time and at any preferred place beyond the textbook and the classroom. The use of social media and social networking applications coincide with the principles as espoused by social constructivists to promote active social engagement, to encourage the students towards collaborative learning and sharing through networking and in communicating to allowing for feedback from a wide audience, and to connect people between the students and their lecturers and peers and the knowledge community for learning beyond the shores of the classroom and the textbooks.

Thus, Facebook becomes not only as a social and networking applications, but Facebook be used as a communicating and learning medium where understandings are socially constructed and shared with the connectivity and the sharing of information and knowledge towards a student-centred learning, with the lecturers (educators) as facilitators to prepare for the knowledge community of the $21^{\text {st }}$ century workforce. Educators can facilitate these social participations and active collaboration of the networked knowledge society of the $21^{\text {st }}$ century to maximize lifelong learning with the following recommendations.

Active - Content Creation: There can be a discussion of the school related topics and modules and an incorporation of additional resources to complement the school curriculum with the use of YouTube 
videos. There can be a combination of both formal and informal learning discussions and communications with the use of the Facebook wall-to-wall postings.

Integrated Platform: There can be different types of content available for a sharing of information and knowledge with one another with guidelines following closely to the curriculum of the school. There can be a mix of visual representations like animations, photographs, videos and links incorporated together with the discussions between and among the students and teachers for use at their own pace and in their own time after school hours. There can be dialogues among the students and teachers as both consultative and collaborative styles of teaching and learning.

Despite the discussions and recommendations, it is also vital to note that classroom and face-to-face communication and learning are not completely being displaced with the advent of social media and networking applications. The face-to-face context of communication and learning is still valued for its trustworthiness for knowing about life and other things related to growing up and working in the future as shown in some of the students' and lecturers' representative responses, too. The future of the technically-driven students and the technically-advanced society means additional research for more blended learning with tapping and leveraging of these collaborative and user-centred applications.

\section{References}

Bosch, T. E. (2009). Using online social networking for teaching and learning: Facebook use at the University of Cape Town. Communication: South African Journal for Communication Theory and Research 35(2), 185-200.

Duffy, P. (2008). Engaging the YouTube Google-Eyed Generation: Strategies for Using Web 2.0 in Teaching and Learning.The Electronic Journal of e-learning 6 (2), 119-130.

Gee, J. P. (2004). New times and new literacies: Themes for a changing world. In A. F. Ball, Bakhtinian Perspectives on Language, Literarcy and Learning (pp. 279-306). Cambridge: Cambridge University Press.

Jonassen, D. H., Peck, K. C., \& Wilson, B. G. (1999). Learning with Technology: A Constructivist Perspective. New Jersey: Merril/Prentice Hall.

Lankshear, C., \&Knobel, M. (2004b). A handbook for teacher research: From design to implementation. London, UK: Open University Presss.

Maloney, E. J. (2007). What Web 2.0 Can Teach Us about Learning.Chronicle of Higher Education 53, (18).

Merriam, S. (1998).Qualitative Research and Case Study Applications in Education. San Francisco: Jossey-Bass.

Mullen \& Wedwick, R. L. (2008). Avoiding the Digital Abyss: Getting started in the classroom with YouTube, Digital Stories and Blogs.Clearing house: A Journal of Educational Strategies, Issues and Ideas 82, (2), 66-69.

Pempek, Y. \&. (2009). College students' social networking experiences on Facebook. Journal of Applied Developmental Psychology, 30(3), 227-238.

Oblinger D. J. (2006).Learning Spaces: Space as a Change Agent.Educause. Retrieved May 2013: http:/ / net.educause.edu/ir/library/pdf/PUB7102a.pdf

O'Hanlon, C. (2007.). If you can't beat_em_join_em. Retrieved Feb 20, 2011, from T.H.E Journal: http://www.thejournal.com/articles/21082

Seitzinger, J. (2006). Be constructive: blogs, podcasts and wikis as constructivist learning tools .Learning solutions .

Selwyn, N. (2009). Faceworking: Exploring students' education-related use of Facebook. Learning, Media and Technology 34(2), 157-174.

Simonson, S. A. (2000). Teaching and Learning at a Distance: Foundations of Distance Education. Upper Saddle River, NJ: Merrill. Singapore Polytechnic.(2009). Singapore youth and social media.Singapore: Singapore.

Stutzman, F. (2005).Our lives, our facebooks. Retrieved from Our lives, our facebooks: [http://www.ibiblio.org/fred/pubs/stutzman_pub6.pdf] 